\title{
George Mitin
}

ORCID: 0000-0002-3124-0352

Instytut Psychologii Rosyjskiej Akademii Edukacji

Moskwa, Rosja

\section{Психологические особенности личностного} и профессионального самоопределения учащихся в условиях инклюзивного образования

\author{
Psychological features of personal and professional \\ self-determination of students in an inclusive education
}

https://doi.org/10.34739/sn.2019.19.05

\begin{abstract}
Аннотация: В статье представлен психологический анализ феномена профессионального самоопределения как новообразования личности, формирующегося в образовательном процессе. Показана необходимость разработки и реализации специальных программ личностного и профессионального самоопределения учащихся с ОВЗ в условиях полисубъектного взаимодействия.

Ключевые слова: личностное и профессиональное самоопределение, инклюзивное образование, ограниченные возможности здоровья, полисубъектная общность, развивающие программы
\end{abstract}

Abstract: The article presents a psychological analysis of the phenomenon of professional self-determination as a feature of personality that is being formed in the educational process. The necessity of the development and implementation of special programs of personal and professional self-determination of students with disabilities in conditions of polysubject interaction is presented.

Keywords: personal and professional self-determination, inclusive education, limited health opportunities, polysubject community, developmental programs

В современном мире огромное количество детей-инвалидов и детей с ограниченными возможностями здоровья и их число продолжает неуклонно расти.

Дети, так остро нуждающиеся в социализации, до недавних пор подвергались серьезной дискриминации, были изолированы от общества, лишены возможности включиться в общеобразовательный процесс, общаться и обучаться вместе со своими сверстниками. Имело место 
и негативное отношение, и предвзятость, и несправедливость, выражающаяся в ограничении их прав на получение образования и невозможности посещать общеобразовательные учреждения. Существующая система образования была ориентирована на «стандартных», «нормальных» детей, отвечающих определенным требованиям, обладающих определенными заявленными возможностями. В настоящее время социализация детей с OB3, т.е. их полноценное участие в жизни общества, включение в общеобразовательный процесс, эффективная самореализация в различных сферах деятельности стали одним из приоритетных направлений государственной образовательной политики современной России.

Вместе с тем отмечается, что в инклюзивном образовании масса объективных и субъективных трудностей. Основные из них:

1. Недостаточно внимания уделяется адаптации пространства обучения, созданию доступной для всех детей с ОВЗ среды.

2. Есть серьезная проблема совмещения темпов преподавания и объема знаний, доступных детям с ОВЗ и детям здоровым. Ребенок с особенностями развития должен помещаться в ту среду, которая на данный момент соответствует возможностям его обучения.

3. Отсутствует специальное медицинское сопровождение в учебном заведении.

4. Необходима подготовка и повышение квалификации педагогов, участвующих в инклюзивном образовании.

5. Крайне неэффективны программы по трудоустройству выпускников с ограниченными возможностями.

6. Не разработаны программы личностного и профессионального самоопределения детей с ОВЗ.

Выявление закономерностей личностно-профессионального самоопределения учащихся, разработка и реализация научнообоснованной системы психолого-педагогической работы в процессе инклюзивного обучения становятся чрезвычайно актуальными.

Особая значимость, сложность и многоплановость процесса самоопределения обусловливают следующие аспекты рассмотрения проблемы: философско-методологические (К.А. Абульханова, Л.И. Анцыферова, Л.П. Буева, А.В. Брушлинский, Э.В. Ильенков, А.Н. Леонтьев, В.А. Лекторский, С.Л. Рубинштейн, В.А. Ядов и др.); общепсихологические (Л.И. Божович, Е.М. Борисова, М.Р. Гинзбург, 
А.М. Кухарчук, И.С. Кон, А.Б. Орлов, С.Л. Рубинштейн, В.Ф: Сафин, Д.И. Фельдштейн и др.); социально-психологические и профессиональные (А.А. Бодалев, В.А., Бодров, Ф.Е. Василюк, И.С. Кон, Е.А. Климов, А.Л. Журавлёв, А.Б. Купрейченко, А.И. Липкина, Н.Н. Обозов, А.В. Петровский, К.К. Платонов, Н.С. Пряжников, Е.Т. Соколова, В.В. Столин, Е.О. Федотова и др.); психолого-культурологические (Л.С. Выготский); психолого-педагогические (А.С. Макаренко, В.А. Сухомлинский, Л.И. Уманский, А.С. Чернышёв, Л.И. Акатов, Т.А. Антопольская, С.Г. Елизаров, Ю.Л. Лобков, С.В. Сарычев, Т.А. Шульгина и др.).

Фундаментальные методологические основы к разработке проблемы самоопределения субъекта были заложены С.Л. Рубинштейном и получили свое дальнейшее развитие в работах К.А. АбульхановойСлавской [1991]: самодетерминация, собственная активность, осознанное стремление занять определенную позицию и др.

С.Л. Рубинштейн первым из отечественных психологов ввел в научный обиход понятие самоопределения, имея в виду, прежде всего, те качества личности, которые определяют ее самостоятельность в выборе жизненных целей и планов. В дальнейшем были определены и основные принципы исследования самоопределения: учет нравственно-ценностного и смысло-жизненного измерения; анализ временного измерения, либо через изучение динамики самосознания субъекта, либо через сопоставление его отношения к своему прошлому, настоящему и будущему; учет стадиальности жизнедеятельности и развития субъекта; учет субъектных свойств человека и группы и пр. В отечественной психологической литературе, несмотря на разнообразие существующих подходов к рассмотрению понятия самоопределения различными авторами, при более детальном анализе становится возможным выделение основополагающих компонентов самоопределения, используемых в большинстве работ.

Так, в работах С. Рубинштейна $[1973,1989]$ большое внимание уделяется идее активности субъекта самоопределения. Вводя понятие «субъекта жизненного пути» и анализируя проблему детерминации поведения, Рубинштейн рассматривает соотношение внешней и внутренней обусловленности активности человека. Именно внутренняя обусловленность, через которую преломляются внешние воздействия, и лежит, по мнению автора, в основе понимания самоопределения. В этом контексте самоопределение выступает как самодетерминация, собственная активность личности. Ведь человек не только находится 
в определенном отношении к миру, но и сам определяет это свое отношение, в чем и заключается сознательное самоопределение человека [Рубинштейн, 1986].

Активно-деятельностный компонент самоопределения исследуется также и в работе И.Ю. Кузнецова. В своем теоретическом анализе автор, опираясь на идеи Б.Ф. Ломова, А.Н. Леонтьева, В.А. Иванникова, приходит к выводу о необходимости рассмотрения самоопределения как собственно психологической деятельности по преобразованию внутренней психологической структуры личности, при этом само это преобразование возможно только при его фиксации во внешней среде. Соответственно, самоопределение - это особая деятельность личности, которая выражается в двух смысловых планах каждого человеческого действия - во внешнем предметном и во внутреннем психологическом [Кузнецов, 2000].

В представлениях Т.М. Буякас [2002] о процессе самоопределения также наличествует идея активности. Автор подчеркивает, что именно в процессе личностного самоопределения "преодолевается потребность искать опору во внешней поддержке и, наоборот, появляется способность полностью опираться на себя - делать самостоятельный выбор" [Буякас, 2002 , с. 32]. В результате человек «пробуждается для жизни», обретает чувство контактной границы между собой и окружающим миром. Такое преодоление и обретение самостоятельности, лежащее в основе самоопределения, характеризует внутреннюю активность личности. Эта активность реализуется внутри некой «целостности» и «полноты», отражающей смысловую сферу субъекта, "которая начинает звучать для него как голос внутренней необходимости" [Буякас, 2002, с. 32]. В этой связи возникает вопрос о ценностно-смысловой наполненности процесса самоопределения.

Ценностно-смысловая основа самоопределения подчеркивается многими авторами. Так, по мнению В.А. Бодрова [1991], необходимо дифференцировать результативную и процессуальную стороны самоопределения личности. Как результат усвоения, закрепления и проявления смысловых личностных образований, самоопределение отражается в изменении и развитии личности. Если же самоопределение понимается не только как результат, но и как процесс, оно выступает как самостоятельная форма активности, направленная на определение и формирование смысло-жизненных ориентаций личности. 
Акцент на ценностно-смысловом компоненте самоопределения личности делает и Л.И. Божович [1986], определяя это понятие как личностное новообразование старшего школьного возраста, которое связано с формированием внутренней позиции взрослого человека. Причем определение смысла своего существования рассматривается как самостоятельная потребность в рамках самоопределения личности, наряду с построением жизненных планов и выбором профессии.

Одна из наиболее проработанных концепций самоопределения личности, предложенная М.Р. Гинзбургом [1994], отражает как ценностносмысловой, так и активно-деятельностный компоненты. Автор, основываясь на работах Н.А. Бердяева, С.Л. Франка, М.М. Бахтина, С.Л. Рубинштейна, кладет в основу рассмотрения понятия самоопределения личности представление о двойственной, духовноматериальной сущности человека, который живет одновременно в двух плоскостях - ценностно-смысловой и пространственно-временной. При этом пространственно-временная плоскость отражает "реальное действо-вание", которое, в свою очередь, является средством реализации ценностей и смыслов. Гинзбург дополняет предлагаемую схему и временным аспектом, рассматривая три компонента - прошлое, настоящее и будущее, через понятие "жизненное поле личности", под которым понимает "совокупность индивидуальных ценностей и смыслов и пространства реального действования - актуального и потенциального, охватывающего прошлое, настоящее и будущее" [Гинзбург, 1994, с. 46]. Необходимо отметить, что прошлое, по мнению автора, существует как воплощение опыта, настоящее отражает действительность и предполагает саморазвитие, а будущее существует как проект, обеспечение смысловой и временной перспективы. В рамках этого подхода личностное самоопределение рассматривается как "содержательное конструирование человеком своего жизненного поля, включающего в себя как совокупность индивидуальных жизненных смыслов, так и пространство реального действия (актуального и потенциального)" [Гинзбург, 1994, с. 47]. В юношеском возрасте вопрос выбора профессионального пути предполагает построение планов на будущее и соотнесение их с настоящим с учетом временной перспективы. Именно в процессе профессионального самоопределения происходит развитие и становление личности. По словам Гинзбурга, "выбор профессии существенным образом характеризует смысловое будущее" [Гинзбург, 1994, с. 50]. 
Существенная роль временного аспекта в самоопределении отмечается и другими авторами. Например, подчеркивается, что в процессе самоопределения «молодые люди входят в позицию проектирования своего будущего. Оно требует специального анализа ими своего прошлого, настоящего и будущего" [Соломадин, Шовкопляс, 1986, с. 115]. В работе Ю.К. Стрелкова указывается, что «время - форма процесса вместе с его переживанием, восприятием, движениями» [Стрелков, 2001, c. 317]. Представления и планы на будущее формируют понятие жизненной перспективы личности. Так, Е.И. Головаха [1988] рассматривает данное понятие как "целостную картину будущего в сложной противоречивой взаимосвязи программируемых и ожидаемых событий, с которыми человек связывает социальную ценность и индивидуальный смысл своей жизни" [Головаха, 1988, с. 26]. Говоря о временном аспекте самоопределения, нельзя не обратиться к понятию жизненного пути, которое во многих работах рассматривается как личностно-временное образование [Ковалев, 1988]. При этом отмечается взаимозависимость самоопределения и жизненного пути личности. В результате самоопределения формируется жизненный путь человека. С другой стороны, именно на жизненном пути происходит самоопределение личности.

Современными исследователями активно обсуждается вопрос временной ориентированности стратегий самоопределения. Так, на основе исследования, проведенного с помощью методики Lifeline, разработанной А.А. Кроником и Е.И. Головахой [1984], и направленного на изучение субъективной картины жизненного пути, Д.А. Леонтьев и Е.В. Шелобанова [2001] делают вывод о существовании двух стратегий самоопределения - ориентации на настоящее и ориентации на будущее. По мнению же О.Б. Бекасова [1995], изучавшего особенности отношения личности к ходу своей жизни, субъективной точкой отсчета является психологическое настоящее. При этом отмечается, что человек, планируя свое будущее, учитывает опыт скорее настоящей, чем прошлой жизни, представляя себя таким, каков он есть сейчас.

Сложность и многоаспектность процесса самоопределения приводит к предположению о существовании различных видов этого явления. В современной психологической литературе наиболее часто выделяются следующие виды самоопределения: "личностное», «жизненное» и "профессиональное самоопределение". При этом 
специальное внимание уделяется проблеме соотношения различных видов самоопределения.

В своей работе С.В. Калинина указывает на необходимость дифференциации понятий жизненного и личностного самоопределения. По мнению автора, жизненное самоопределение включает в себя "не только выбор и реализацию человеком тех или иных социальных ролей, но и социальных стереотипов, выбор жизненного стиля и самого образа жизни, того или иного жизненного стереотипа" [Калинина, 1998, с. 9]. В свою очередь личностное самоопределение понимается ею как процесс обретения "самобытного "образа Я", постоянное развитие этого образа и утверждение его среди окружающих людей" [Калинина, 1998, с. 9].

Говоря о профессиональном, жизненном и личностном самоопределении как об основных типах самоопределения, Н.С. Пряжников подчеркивает, что "на высших уровнях своего проявления эти типы почти взаимопроникают друг в друга" [Пряжников, 1996]. Вместе с тем, эта важная идея о наличии взаимосвязи и взаимовлияния между различными видами самоопределения требует, с нашей точки зрения, дальнейшей проработки. К примеру, остается нераскрытым процесс взаимодействия разных видов самоопределения на других уровнях развития. Неясно также, каким образом происходит и в чем выражается процесс взаимопроникновения.

Идея взаимосвязанности, взаимовлияния как основной механизм соотношения различных видов самоопределения обсуждается и другими авторами. Так, А.К. Маркова не только констатирует, что все виды самоопределения находятся В постоянном взаимодействии, но и указывает, как это взаимодействие осуществляется. По ее мнению, различные виды самоопределения чаще всего "происходят одновременно, меняясь местами как причина и следствие" [Маркова, 1996, с. 58]. Однако, в некоторых случаях различные виды самоопределения могут предшествовать друг другу. Например, личностное самоопределение может предшествовать профессиональному, тем самым, способствуя ему. Согласно А.К. Марковой, в основе различных видов самоопределения лежит жизненное самоопределение, которое начинается с первого дня жизни как «выполнение человеком своего предназначения». В зарубежной психологии исследованию разных сторон личностного самоопределения посвящены работы А. Адлера, А. Маслоу, Г. Олпорта, В. Франкла, Э. Фромма, Э. Эриксона, А. Эспинозы, и др. При этом личностное самоопределение очень близко по своему 
содержанию к понятию «личностная», «индивидуальная» или «психосоциальная идентичность». Проблема профессионального самоопределения, его структуры обсуждается в работах Е. Бордина, А. Маслоу, Э. Роу, Д. Сьюпера, Д. Тидемана, О'Хара, Дж. Холланда, Э. Шпрангера и др.

Вопрос о том, какой именно вид самоопределения является базисным, основополагающим рассматривается в работах Л.М. Митиной [2014]. Методологически центральной в концепции профессионального развития и самоопределения личности Л.М. Митиной является идея о внутренней детерминации и единстве личностного и профессионального самоопределения как взаимодополняющих и взаимополагающих процессов, попеременно являющихся друг для друга то средством, то результатом развития на разных этапах онтогенеза. Основой развивающих программ профессионального самоопределения учащихся является, по мнению автора, полисубъектная общность «учитель-ученик».

Современная образовательная парадигма инклюзивной школы требует иного подхода к решению вопросов психологической поддержки учащихся и учителей на всех этапах профессионального становления и особенно на этапе личностного и профессионального самоопределения учащихся старшей школы. Это обусловлено тем, что переход на субъектсубъектные отношения в учебно-профессиональном взаимодействии объективно становится возможным при личностной готовности каждой из взаимодействующих сторон выстраивать партнёрские отношения через совместное проектирование образовательной, развивающей среды и продуктивных моделей сотрудничества. При таком подходе к построению образовательного процесса для комплексного решения задач психологической поддержки участников взаимодействия недостаточно эпизодических включений специалистов-психологов в решение конкретных возникающих ситуаций. Следовательно, необходима целостная система социально-психологического и психологопедагогического сопровождения личностно-профессионального развития субъектов учебного взаимодействия, поэтапно обеспечивающая достижение индивидуальных целей каждой из взаимодействующих сторон, а также формирующая психологическую готовность субъектов учебно-воспитательного процесса выстраивать и поддерживать партнёрские отношения в течение всего периода обучения в вузе.

K сожалению, в большинстве инклюзивных школ работа личностного и профессионального самоопределения с учителями 
проводится минимальная, а с учащимися - только формальная. Случаи общей развивающей работы совместно и с учителями, и с учащимися единичны и несистематизированы. Поэтому одной из центральных задач инклюзивного образования является разработка и реализация программ личностного и профессионального самоопределения учащихся с ОВЗ в условиях полисубъектного взаимодействия «учитель-ученик».

\section{Literatura [Литература]}

Abul'khanova-Slavskaya K.A., (1991), Strategiya zhizni, Moskva. [Абульханова-Славская К.А., (1991), Стратегия жизни, Москва].

Bodrov V.A., (1991), Psikhologicheskiye issledovaniya professionalizatsii lichnosti, v: Psikhologicheskiye issledovaniya problemy formirovaniya lichnosti professionala, Bodrova V.A., (red.), IP RAN, Moskva. [Бодров B.A., (1991), Психологические исследования профессионализации личности, в: Психологические исследования проблемы формиро-вания личности профессионала, Бодрова В.А., (ред.), ИП РАН, Москва].

Ginzburg M.R., (1994), Psikhologicheskoye soderzhaniye lichnostnogo samoopredeleniya, Voprosy psikhologii, № 3. [Гинзбург М.P., (1994), Психологическое содержание личностного самоопределения, Вопросы психологии, № 3].

Markova A.K., (1996), Psikhologiya professionalizma, Moskva. [Маркова А.К., (1996), Психология профессионализма, Москва].

Mitin G.V., (2017), Prevention and correction of antisocial behavior of students in different educational environments, Sofia.

Mitina L.M., (2014), Psikhologiya lichnostno-professional'nogo razvitiya sub"yektov obrazovaniya: monografiya, Nestor-Istoriya, Moskva - Sankt Peterburg. [Митина Л.М., (2014), Психология личностнопрофессионального развития субъектов образования: монография, Нестор-История, Москва - Санкт Петербург].

Pryazhnikov N.S., (1996), Professional'noye i lichnostnoye samoopredeleniye, Feniks, Moskva, [Пряжников Н.С., (1996), Профрессиональное и личностное самоопределение, Феникс, Москва].

Rubinshteyn S.L., (1986), Printsipy tvorcheskoy samodeyatel'nosti. K filosofskim osnovam sovremennoy pedagogiki, Voprosy psikhologii, № 4. [Рубинштейн С.Л., (1986), Принципы творческой самодеятельности. $K$ философским основам современной педагогики, Вопросы психологии, № 4. 